\title{
The Influence of Iso-Butanol Blending with a Reference Gasoline and its Surrogate on Spark-Ignition Engine Performance
}

\author{
Christian A. Michelbach*, Alison S. Tomlin
}

School of Chemical and Process Engineering, University of Leeds, Leeds LS2 9JT, United Kingdom

\section{Supplementary Material:}

Figures $\mathrm{S} 1$ and S2 show normalised local $\mathrm{OH}$ sensitivity analysis results for a zero-dimensional homogeneous batch reactor (designed to model autoignition within an RCM), for 5-C iB10 and 5-C iB05 fuels, respectively. These analyses are provided at a compressed pressure of 20 bar and temperatures of 710, 770, and $830 \mathrm{~K}$. Figure S1 shows that, for iB10, the hydrogen abstraction from the primary iso-butanol $\left(\mathrm{iC}_{4} \mathrm{H}_{8} \mathrm{OH}\right)$ site by an $\mathrm{OH}$ radical is shown to be the dominant fuel reaction and highly negatively sensitive, despite iso-butanol only contributing $10 \%$ of the blend's volume. Primary hydroxybutyl radicals $\left(\mathrm{iC}_{4} \mathrm{H}_{8} \mathrm{OH}-\right.$ 1) and $\mathrm{H}_{2} \mathrm{O}$ are formed via this reaction. The further hydrogen abstraction of $\mathrm{iC}_{4} \mathrm{H}_{8} \mathrm{OH}-1$ to produce a relatively unreactive aldehyde and a $\mathrm{HO}_{2}$ radical is also highly negatively sensitive. These reactions provide an example of iso-butanol's behaviour as a radical scavenger during autoignition, consuming highly reactive $\mathrm{OH}$ radicals to form less reactive $\mathrm{HO}_{2}$ radicals and aldehydes. This behaviour is important in generating the octane boosting qualities of iso-butanol but limits the generation of NTC behaviour ${ }^{1,2}$.

Sensitivity analysis results for 5-C iB05, as shown in figure S2, do not exhibit the same dominance by iso-butanol reactions (which appear to be much less sensitive). Instead, reaction sensitivities appear very similar to those shown in a previous RCM IDT study for 5- $\mathrm{C}^{2}$. For the iB05 (much like 5-C), the dominant fuel reactions are largely hydrogen abstractions of iso-octane $\left(\mathrm{iC}_{8} \mathrm{H}_{18}\right)$ and $\mathrm{n}$ heptane $\left(\mathrm{nC}_{7} \mathrm{H}_{16}\right)$ by an $\mathrm{OH}$ radical. At low temperatures and within the NTC region, reactivity is promoted by abstraction from the primary and secondary iso-octane sites, which may initiate chain branching further down the respective low temperature oxidation pathways. On the other hand, abstraction from the tertiary iso-octane site lacks a low temperature chain branching pathway, ultimately resulting in the formation of relatively unreactive olefin species from the initial iso-octane and $\mathrm{OH}$ radical ${ }^{3}$. Hydrogen abstractions from $\mathrm{n}$-heptane display a highly positive sensitivity throughout the low temperature to NTC region, owing to the fuel's importance in the driving of first-stage ignition (cool flame) at low temperatures. While sensitivity analysis of iB05 RCM autoignition is not dominated by iso-butanol fuel reactions, hydrogen abstraction from the primary iso-butanol does appear in the list of most sensitive reactions, although it is much less negatively sensitive than in the case of iB10. Therefore, in the case of iB05, the scavenging of reactive $\mathrm{OH}$ radicals from the radical pool by isobutanol may supress the NTC response, delaying it until increased temperatures facilitate a growing radical pool. This leads to the delayed NTC witnessed in IDT measurements ${ }^{2}$ (relative to $5-\mathrm{C}$ ) and therefore, the cross-over witnessed between iB05 and iB10 IDTs and KNs. 


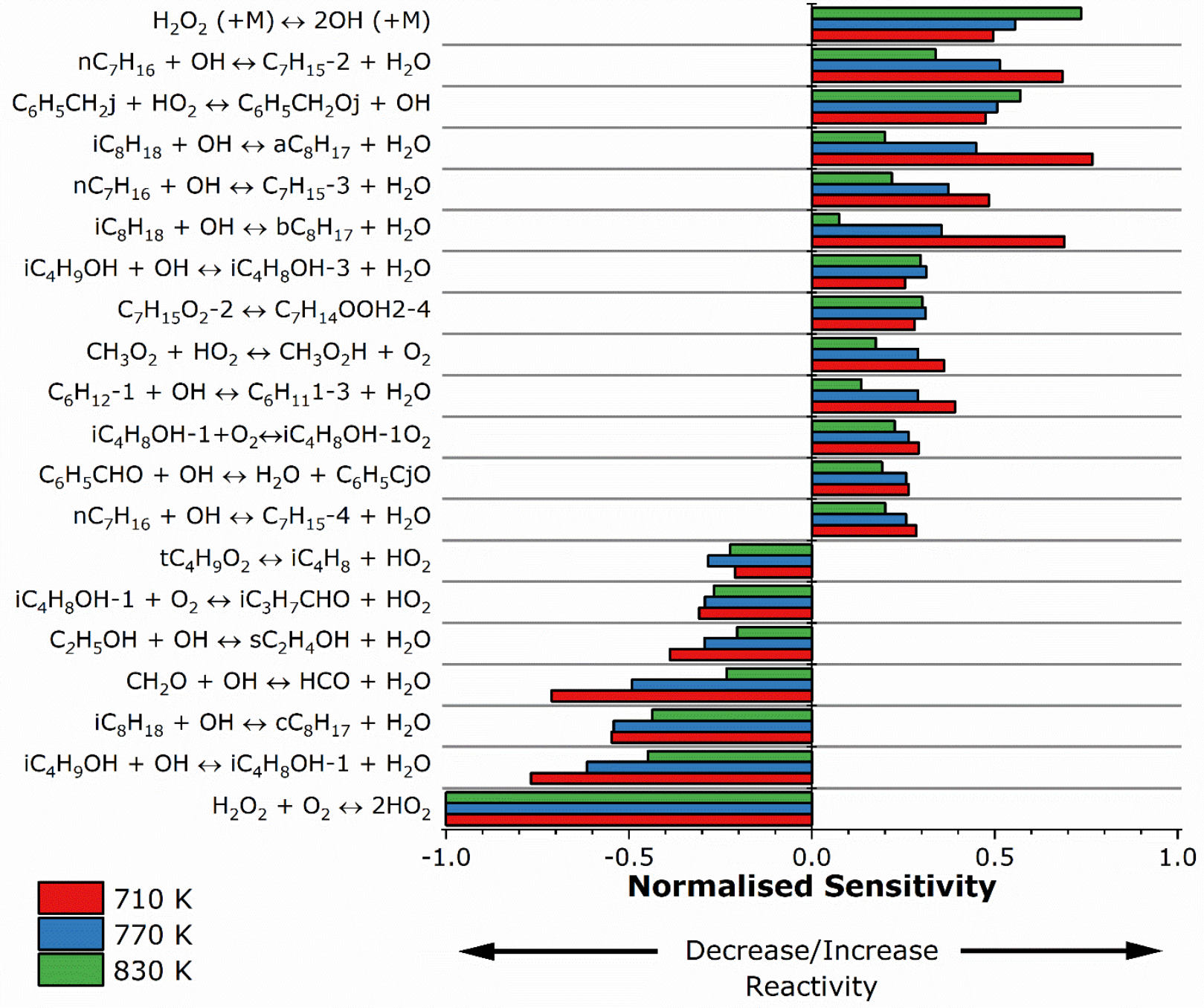

Figure S1. Normalised local OH sensitivity analysis of zero-dimensional RCM IDT modelling, results for iB10 at 710-830 K. Pc=20 bar, $\Phi=1$. 


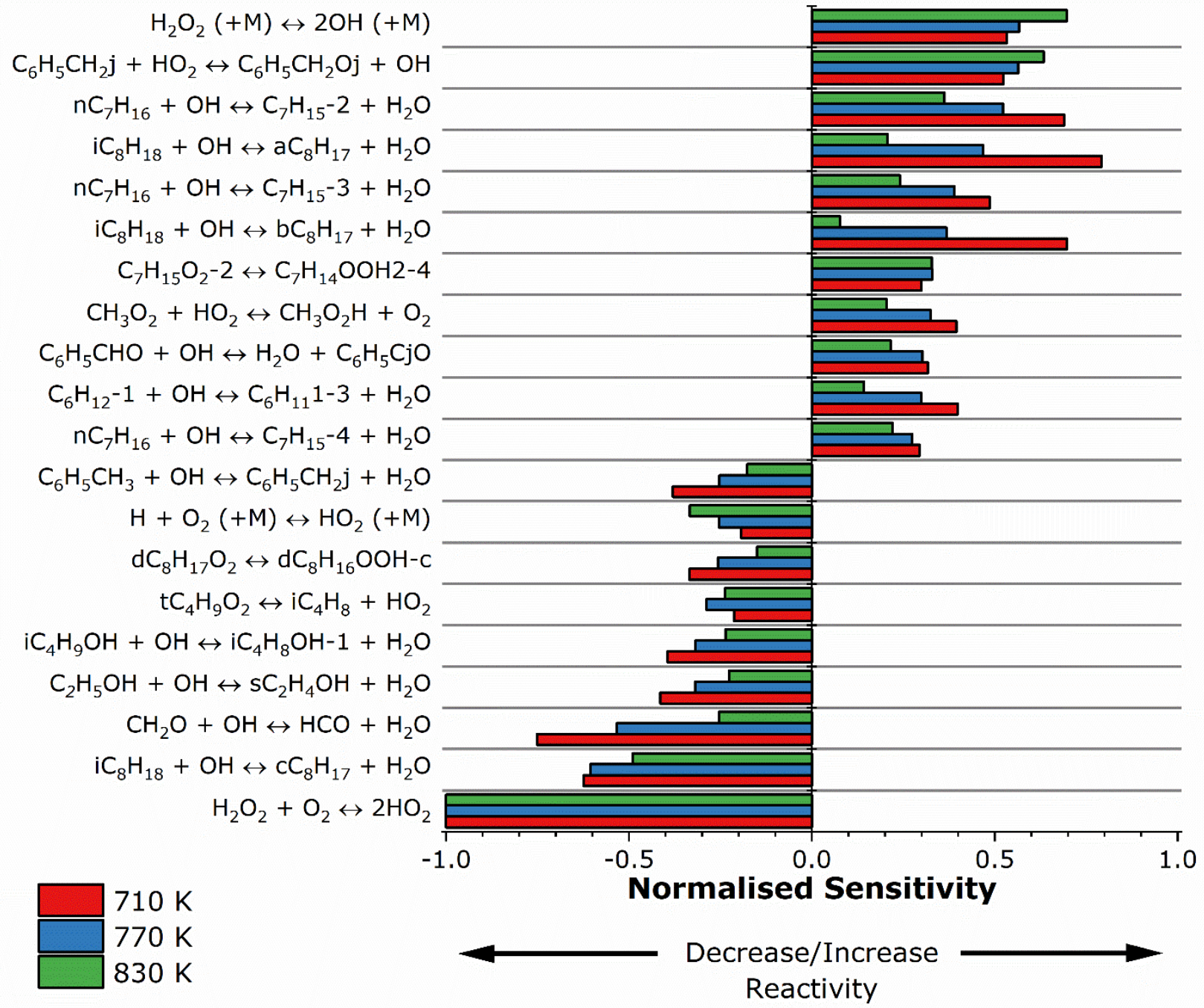

Figure S2. Normalised local OH sensitivity analysis of zero-dimensional RCM IDT modelling, results for $\mathrm{iB} 05$ at $710-830 \mathrm{~K}$. Pc=20 bar, $\Phi=1$. 


\section{References}

(1) Sarathy, S. M.; Oßwald, P.; Hansen, N.; Kohse-Höinghaus, K. Alcohol Combustion Chemistry. Prog. Energy Combust. Sci. 2014, 44, 40-102. https://doi.org/10.1016/j.pecs.2014.04.003.

(2) Michelbach, C.; Tomlin, A. An Experimental and Kinetic Modeling Study of the Ignition Delay and Heat Release Characteristics of a Five Component Gasoline Surrogate and Its Blends with Iso-Butanol within a Rapid Compression Machine. Int. J. Chem. Kinet. 2021, 53 (6), 787-808. https://doi.org/10.1002/kin.21483.

(3) Atef, N.; Kukkadapu, G.; Mohamed, S. Y.; Rashidi, M. A.; Banyon, C.; Mehl, M.; Heufer, K. A.; Nasir, E. F.; Alfazazi, A.; Das, A. K.; Westbrook, C. K.; Pitz, W. J.; Lu, T.; Farooq, A.; Sung, C.-J.; Curran, H. J.; Sarathy, S. M. A Comprehensive Iso-Octane Combustion Model with Improved Thermochemistry and Chemical Kinetics. Combust. Flame 2017, 178, 111134. https://doi.org/10.1016/j.combustflame.2016.12.029. 